\title{
Variation of poorly ventilated lung units (silent spaces) measured by electrical impedance tomography to dynamically assess recruitment
}

\author{
Savino Spadaro ${ }^{1 *}$ (D) Tommaso Mauri ${ }^{2}$, Stephan H. Böhm ${ }^{4}$, Gaetano Scaramuzzo ${ }^{1}$, Cecilia Turrini ${ }^{1}$, \\ Andreas D. Waldmann ${ }^{3}$, Riccardo Ragazzi ${ }^{1}$, Antonio Pesenti ${ }^{2}$ and Carlo Alberto Volta ${ }^{1}$
}

\begin{abstract}
Background: Assessing alveolar recruitment at different positive end-expiratory pressure (PEEP) levels is a major clinical and research interest because protective ventilation implies opening the lung without inducing overdistention. The pressure-volume (P-V) curve is a validated method of assessing recruitment but reflects global characteristics, and changes at the regional level may remain undetected. The aim of the present study was to compare, in intubated patients with acute hypoxemic respiratory failure (AHRF) and acute respiratory distress syndrome (ARDS), lung recruitment measured by P-V curve analysis, with dynamic changes in poorly ventilated units of the dorsal lung (dependent silent spaces [DSSs]) assessed by electrical impedance tomography (EIT). We hypothesized that DSSs might represent a dynamic bedside measure of recruitment.
\end{abstract}

Methods: We carried out a prospective interventional study of 14 patients with AHRF and ARDS admitted to the intensive care unit undergoing mechanical ventilation. Each patient underwent an incremental/decremental PEEP trial that included five consecutive phases: PEEP 5 and $10 \mathrm{cmH}_{2} \mathrm{O}$, recruitment maneuver + PEEP $15 \mathrm{cmH}_{2} \mathrm{O}$, then PEEP 10 and $5 \mathrm{cmH}_{2} \mathrm{O}$ again. We measured, at the end of each phase, recruitment from previous PEEP using the P-V curve method, and changes in DSS were continuously monitored by EIT.

Results: PEEP changes induced alveolar recruitment as assessed by the P-V curve method and changes in the amount of DSS $(p<0.001)$. Recruited volume measured by the P-V curves significantly correlated with the change in DSS $\left(r_{s}=0.734, p<0.001\right)$. Regional compliance of the dependent lung increased significantly with rising PEEP (median PEEP $5 \mathrm{cmH}_{2} \mathrm{O}=11.9$ [IQR 10.4-16.7] $\mathrm{ml} / \mathrm{cmH}_{2} \mathrm{O}$, PEEP $15 \mathrm{cmH}_{2} \mathrm{O}=19.1$ [14.2-21.3] $\mathrm{ml} / \mathrm{cmH}_{2} \mathrm{O} ; p<0.001$ ), whereas regional compliance of the nondependent lung decreased from PEEP $5 \mathrm{cmH}_{2} \mathrm{O}$ to PEEP $15 \mathrm{cmH}_{2} \mathrm{O}$ (PEEP $5 \mathrm{cmH}_{2} \mathrm{O}=25.3$ [21.3-30.4] $\mathrm{ml} / \mathrm{cmH}_{2} \mathrm{O}$, PEEP $15 \mathrm{cmH}_{2} \mathrm{O}=20.0$ [16.6-22.8] $\mathrm{ml} / \mathrm{cmH}_{2} \mathrm{O} ; p<0.001$ ). By increasing the PEEP level, the center of ventilation moved toward the dependent lung, returning to the nondependent lung during the decremental PEEP steps.

Conclusions: The variation of DSSs dynamically measured by EIT correlates well with lung recruitment measured using the P-V curve technique. EIT might provide useful information to titrate personalized PEEP.

Trial registration: ClinicalTrials.gov, NCT02907840. Registered on 20 September 2016.

Keywords: Pressure-volume curve, Electrical impedance tomography, Acute respiratory failure, Acute respiratory distress syndrome, Personalized medicine, Positive end-expiratory pressure

\footnotetext{
* Correspondence: savinospadaro@gmail.com

${ }^{1}$ Department of Morphology Surgery and Experimental Medicine, Section of

Anesthesia and Intensive Care, University of Ferrara, 8, Aldo Moro, 44124

Ferrara, Italy

Full list of author information is available at the end of the article
} 


\section{Background}

Ventilation of patients with acute hypoxemic respiratory failure (AHRF) and acute respiratory distress syndrome (ARDS) [1] should provide adequate gas exchange while minimizing the risk of ventilator-induced lung injury (VILI) $[2,3]$. Mechanisms underlying VILI include tidal collapse and reopening of unstable lung units, overstretch of the "baby lung" [4], and heterogeneous ventilation that increases regional transpulmonary pressure [5-7]. Strategies aimed at "opening the lung and keeping it open" by means of alveolar recruitment may reduce the risk of VILI $[3,5,8]$, and positive end-expiratory pressure (PEEP) set to stabilize re-aerated alveoli while avoiding overdistention might be a key aspect of protective ventilation [9]. Despite a recent large trial that showed the potential harmfulness of a maximal recruitment strategy [10], other studies in which researchers compared higher versus lower PEEP levels did not yield definitive results $[11,12]$. One reason could have been the pathophysiologic heterogeneity of ARDS, with large interindividual variations in the extent and distribution of alveolar collapse that reduced clinical benefits of arbitrarily higher PEEP levels [13]. Thus, a bedside method of accurately assessing recruitment and overdistention might be fundamental to the design of future studies applying personalized "optimum" PEEP levels [2].

Lung recruitment may be evaluated by performing pressure-volume $(\mathrm{P}-\mathrm{V})$ curves of the respiratory system [14]. Several studies have validated the P-V curve method as a reliable estimate of PEEP-induced changes in aerated lung volume [15-20]. However, P-V curves are relatively complex to perform, time-consuming, noncontinuous, and not feasible in spontaneously breathing patients.

Recently, electrical impedance tomography (EIT) has been introduced as a bedside radiation-free technique that provides dynamic regional information on changes in lung aeration, ventilation, and heterogeneity [21]. EIT can identify and quantify breath-by-breath poorly ventilated lung units, also called silent spaces. In a recent study, researchers suggested that in postoperative patients with healthy lungs, silent spaces in the dependent lungs may indicate atelectasis, whereas increase in silent spaces in the nondependent lungs may correspond to overdistention [22].

In this study, we compared, in intubated patients with AHRF and ARDS, lung recruitment measured by P-V curve analysis with dynamic changes in poorly ventilated units of the dorsal lung (dependent silent spaces [DSSs]) assessed by EIT. We hypothesized that changes in DSS might represent a dynamic bedside measure of lung recruitment and collapse.

\section{Methods}

\section{Study population}

Patients with AHRF and ARDS were enrolled after we obtained approval from the Ethics Committee of the
Sant'Anna Hospital, Ferrara, Italy (protocol no. 141285), and written informed consent according to local regulations. The study (registered with ClinicalTrials.gov [NCT02907840]) was conducted between December 2015 and October 2016 in accordance with the Declaration of Helsinki.

Inclusion criteria were adult patients (aged $\geq 18$ years) who were deeply sedated and paralyzed as per clinical decision with a ratio of partial pressure of oxygen in arterial blood to fraction of inspired oxygen $\left(\mathrm{PaO}_{2} /\right.$ $\left.\mathrm{FiO}_{2}\right) \leq 300 \mathrm{mmHg}$ and clinical PEEP $\geq 5 \quad \mathrm{cmH}_{2} \mathrm{O}$ [1]. Exclusion criteria are listed in Additional file 1. At enrollment, we collected demographic and clinical data of each patient.

At the beginning of the study, patients were ventilated using the SERVO-i ventilator (Maquet Critical Care, Solna Sweden) in volume-controlled ventilation with tidal volume $\left(\mathrm{V}_{\mathrm{T}}\right)$ of $6-8 \mathrm{ml} / \mathrm{kg}$ of predicted body weight. $\mathrm{FiO}_{2}$ was set to obtain an arterial oxygen saturation of 90-95\% [23] and was kept constant during the entire study protocol.

\section{EIT monitoring}

EIT signals were recorded continuously throughout the study protocol using the commercially available 32electrode Swisstom $\mathrm{BB}^{2}$ device (Swisstom, Landquart, Switzerland). The sampling rate used was $48 \mathrm{~Hz}$. The individual's height and weight determined the image reconstruction matrix of the respective patient [24]. EIT lung images containing $32 \times 32$ pixels, were displayed at the patient's bedside. We selected four horizontal parallel regions of interest (ROIs) within the chest contour: ROI 1 (ventral), ROI 2 (central ventral), ROI 3 (central dorsal), and ROI 4 (dorsal).

\section{Study protocol}

During the study protocol, patients were fully sedated and paralyzed using continuous infusion of propofol, morphine, and rocuronium bromide. The study protocol consisted of five consecutive phases (Additional file 1: Figure S1), each lasting 20 minutes, to reach steady-state conditions:

1. PEEP $5 \mathrm{cmH}_{2} \mathrm{O}$ (PEEP5 incremental phase)

2. PEEP $10 \mathrm{cmH}_{2} \mathrm{O}$ (PEEP10 incremental phase)

3. Recruitment maneuver (RM) + PEEP $15 \mathrm{cmH}_{2} \mathrm{O}$

4. PEEP $10 \mathrm{cmH}_{2} \mathrm{O}$ (PEEP10 decremental phase)

5. PEEP $5 \mathrm{cmH}_{2} \mathrm{O}$ (PEEP5 decremental phase)

At the end of each phase, we collected ventilation parameters, hemodynamics, and arterial blood gases and performed P-V curve analysis and change in endexpiratory lung volume $(\triangle \mathrm{EELV})$ measurements. 


\section{Recruitment maneuver}

As previously described, an RM consisting of the application of continuous positive airway pressure of 40 $\mathrm{cmH}_{2} \mathrm{O}$ for 40 seconds was performed (step 3) $[25,26]$.

\section{EIT measurement}

EIT data were continuously recorded and analyzed offline. The following EIT-derived parameters were measured:

1. Dependent and nondependent "silent spaces," as previously described [22]: For each breath, pixels within the ROI showing impedance changes $<10 \%$ of the maximal impedance change were determined. The silent spaces were categorized into dependent silent spaces (DSSs) and nondependent silent spaces (NSSs) by a virtual line perpendicular to the gravity vector passing through the center of ventilation (CoV; see details see below). The amount of silent spaces was expressed as a percentage of the entire ROI. The final value of NSS and DSS was the average of 20 consecutive representative breaths during the last minutes of each phase.

2. CoV, which represents the geometrical focal point of the overall ventilation: This index is expressed as a percentage of the anteroposterior extension of the identified lung region, where $0 \%$ refers to ventilation occurring only in the most ventral lung region and $100 \%$ refers to ventilation in the most dorsal part [21, 27, 28] (see also Additional file 1).

3. Region of interest tidal volume $\left(\mathrm{V}_{\mathrm{TROI}}\right)$ in milliliters computed by multiplying global $\mathrm{V}_{\mathrm{T}}$ by the fraction of tidal distribution of impedance signal in each ROI: Dependent and nondependent tidal volumes ( $V_{\text {TDEP }}$ and $V_{\text {TNON-DEB }}$ respectively) were obtained by summing the $V_{T}$ values reaching the corresponding ROIs.

4. Tidal distribution index (TDI), or anteroposterior ventilation ratio [21]: This is defined as the ratio between $\mathrm{V}_{\mathrm{T}}$ delivered to the nondependent and dependent lung regions. This index is used to evaluate the homogeneity of tidal breath distribution.

5. Regional dynamic compliance for each ROI $\left(\mathrm{Compl}_{\mathrm{ROIn}}\right)$ and for the dependent and nondependent lung: This was calculated as follows: Compl $\mathrm{ROIn}_{\mathrm{R}}=\mathrm{Vt}_{\mathrm{ROIn}} /$ driving pressure $[29,30]$.

6. Changes in end-expiratory lung impedance $(\triangle E E L I)$ at different PEEP levels, as previously described [31].

\section{Lung mechanics measurements}

A heated pneumotachograph (Fleisch type 2; Fleisch, Lausanne, Switzerland) was used to measure flow. $V_{T}$ values were obtained by time integration of the flow signal. The pressure signal was recorded at the airway opening (Pao) via a rigid polyethylene catheter connected to a differential pressure transducer (200B; Raytech Instruments Inc., Vancouver, BC, Canada). Data were recorded at $100 \mathrm{~Hz}$ and analyzed offline to obtain the following data:

1. The P-V curve was determined by using the constant flow method [16], implying a continuous low-flow lung inflation. A third-degree polynomial equation $\left(\Delta \mathrm{V}=\mathrm{a}+\mathrm{b} \times \mathrm{PaO}+\mathrm{c} \times \mathrm{Pao}^{2}\right)$ was fitted to the P-V curves.

2. $\triangle E E L V$ was computed as the difference between the volume in the lung at a defined PEEP level and relaxation volume on zero PEEP, as previously described by Ranieri et al. [16, 32].

3. Recruitment/derecruitment: Recruitment was identified as the upward shift along the volume axis of the P-V curve on a given PEEP relative to the curve on the previous PEEP level and quantified as the increase in volume at the same Pao of 20 $\mathrm{CmH}_{2} \mathrm{O}$ [32]. Derecruitment was identified as the downward shift of the curve during decreasing PEEP levels. Recruited/derecruited volume was expressed as the difference in volume in the lungs, referring to the previous stage at the same level of Pao.

4. Respiratory system compliance (Crs), calculated as follows: $\mathrm{Crs}=\mathrm{V}_{\mathrm{T}} /$ (Pplat - PEEPtot), with Pplat being plateau pressure and PEEPtot being the total positive end-expiratory pressure at the end of end-inspiratory and end-expiratory holds, respectively, each lasting 5 seconds.

\section{Statistical analysis}

Sample size was calculated assuming correlation coefficients between changes in lung volumes assessed by EIT and spirometry with a type I error rate of 0.01 and type II error rate of 0.20 ( $80 \%$ power) using the sampling correlation coefficient test in MedCalc (MedCalc Software, Ostend, Belgium). The estimated correlation coefficient used in our sample size calculation was based on a previous study $(r=0.92)$ [33]. Thus, a minimum of eight patients was required. We planned to enroll an additional $30 \%$ of the estimated patients to account for patients unable to complete the entire protocol. Therefore, the total number of patients to be recruited was 14 .

A nonnormal distribution was assumed, owing to the small sample size $(n<30)$. Data are presented as median and IQR. Friedman's nonparametric test for repeated measures was used to analyze differences between the five phases. If a significant difference appeared, conditions were compared in pairwise fashion using the Wilcoxon test with the Bonferroni correction. Linear regression and Spearman's coefficient $\left(r_{\mathrm{s}}\right)$ were calculated to evaluate potential correlations between variables.

Statistical analyses were performed using IBM SPSS Statistics version 20.0 software (IBM, Armonk, NY, 
USA). In all statistical analyses, a two-tailed test was performed, and a $p$ value $\leq 0.05$ was considered statistically significant. Additional details on the methods are provided in Additional file 1.

\section{Results}

\section{Patients' characteristics}

A total of 14 patients were enrolled, 12 (86\%) of whom were within 1 week from diagnosis of AHRF or ARDS. The patients' main clinical characteristics are reported in Table 1. At enrollment, all patients had a $\mathrm{PaO}_{2} / \mathrm{FiO}_{2}<300 \mathrm{mmHg}$, with five of them (36\%) having a $\mathrm{PaO}_{2} / \mathrm{FiO}_{2}<200 \mathrm{mmHg}$. The level of clinical PEEP was $7 \pm 2 \mathrm{cmH}_{2} \mathrm{O}$. Five patients (36\%) showed bilateral infiltrates on chest $\mathrm{x}$-rays fulfilling the Berlin ARDS criteria [1]. The protocol did not have to be interrupted in any patient because of hemodynamic instability or worsening of other clinical parameters.

\section{Effects of PEEP on respiratory mechanics, gas exchange,} and hemodynamics

The effects of the different PEEP levels on respiratory mechanics, gas exchange, and hemodynamics are summarized in Table 2. Although Pplat increased with rising PEEP $(p<0.001)$, the driving pressure did not change significantly $(p=0.100)$ throughout the study protocol. Accordingly, Crs did not exhibit any significant variation $(p=0.100)$. The same was true for $\mathrm{PaO}_{2} / \mathrm{FiO}_{2}(p=0.611)$.

\section{Correlation between recruitment by $\mathrm{P}-\mathrm{V}$ curve and changes of silent spaces}

PEEP had a profound effect on silent spaces: Higher levels of PEEP were associated with a decrease in silent spaces, whereas the opposite was true when reducing the level of PEEP (Table 3, Fig. 1). Changes in silent spaces occurred only in the dependent lung regions $(p \leq 0.001)$; furthermore, the RM reduced DSS compared with the same level of PEEP prior to the RM (Table 3). Incremental and decremental PEEP steps showed effects on the recruited and de-recruited lung volumes, as measured by the P-V curve method, which correlated with the EIT-derived changes of DSS $\left(r_{\mathrm{s}}=0.734, p<0.001\right)$ (Table 3, Fig. 2).

\section{Effects of PEEP on EIT-derived data}

EIT data are summarized in Table 3. The regional distribution of ventilation changed during the protocol. By increasing the PEEP level, the CoV moved toward the dependent lung, whereas the $\mathrm{CoV}$ returned to the nondependent lung during the decremental PEEP steps. TDI also showed a shift of ventilation toward the dependent lung at higher PEEP levels $(p<0.001)$. Regional compliance of the dependent lung increased significantly with rising PEEP, whereas regional compliance of the nondependent lung decreased from PEEP 5 to PEEP $15(p<0.001)$.

ROI 4 exhibited the highest potential for recruitment because its regional compliance almost doubled. By

Table 1 Patients' main characteristics

\begin{tabular}{|c|c|c|c|c|c|c|c|c|c|c|c|}
\hline Patient & Sex & $\begin{array}{l}\text { Age } \\
\text { (years) }\end{array}$ & BMI & $\begin{array}{l}\text { SAPS II score } \\
\text { (at ICU } \\
\text { admission) }\end{array}$ & $\begin{array}{l}\text { SOFA score } \\
\text { (on day } \\
\text { of study) }\end{array}$ & $\begin{array}{l}\text { Etiology of acute } \\
\text { respiratory failure }\end{array}$ & $\begin{array}{l}\text { Days of } \\
\text { intubation } \\
\text { before } \\
\text { study }\end{array}$ & $\begin{array}{l}\text { ARDS } \\
\text { (yes or no) }\end{array}$ & $\begin{array}{l}\mathrm{PaO}_{2} / \mathrm{FiO}_{2} \\
(\mathrm{mmHg})^{\mathrm{a}}\end{array}$ & $\begin{array}{l}\text { PEEP } \\
\left(\mathrm{cmH}_{2} \mathrm{O}\right)^{\mathrm{a}}\end{array}$ & Outcome \\
\hline 1 & M & 79 & 26 & 33 & 8 & Thoracic trauma & 7 & Yes & 160 & 8 & Nonsurvivor \\
\hline 2 & M & 90 & 29 & 46 & 7 & Sepsis & 1 & Yes & 205 & 10 & Survivor \\
\hline 3 & M & 71 & 29 & 30 & 10 & $\begin{array}{l}\text { Postoperative } \\
\text { respiratory failure }\end{array}$ & 2 & No & 230 & 7 & Survivor \\
\hline 4 & $\mathrm{~F}$ & 80 & 35 & 22 & 9 & Postoperative respiratory failure & 5 & Yes & 263 & 8 & Survivor \\
\hline 5 & M & 69 & 33 & 30 & 4 & $\begin{array}{l}\text { Postoperative } \\
\text { respiratory failure }\end{array}$ & 2 & No & 168 & 8 & Survivor \\
\hline 6 & M & 66 & 24 & 40 & 6 & Sepsis & 1 & No & 294 & 6 & Survivor \\
\hline 7 & $\mathrm{~F}$ & 85 & 19 & 38 & 5 & Septic shock & 1 & No & 273 & 7 & Survivor \\
\hline 8 & $\mathrm{~F}$ & 80 & 33 & 63 & 10 & $\begin{array}{l}\text { Sepsis in hemorrhagic } \\
\text { shock }\end{array}$ & 4 & Yes & 256 & 10 & Survivor \\
\hline 9 & $\mathrm{~F}$ & 76 & 24 & 33 & 8 & Sepsis & 2 & No & 258 & 7 & Nonsurvivor \\
\hline 10 & $\mathrm{~F}$ & 75 & 22 & 35 & 5 & $\begin{array}{l}\text { Postoperative } \\
\text { respiratory failure }\end{array}$ & 1 & No & 239 & 6 & Survivor \\
\hline 11 & $\mathrm{~F}$ & 72 & 26 & 38 & 10 & Pneumonia & 6 & No & 175 & 6 & Survivor \\
\hline 12 & $\mathrm{~F}$ & 78 & 35 & 38 & 11 & Pneumonia & 4 & No & 141 & 6 & Survivor \\
\hline 13 & M & 71 & 34 & 30 & 9 & Pancreatitis & 2 & Yes & 98 & 12 & Survivor \\
\hline 14 & M & 60 & 25 & 29 & 3 & Sepsis & 9 & No & 290 & 6 & Survivor \\
\hline Mean \pm SD & $7 \mathrm{M} / 7 \mathrm{~F}$ & $75 \pm 8$ & $28 \pm 5$ & $36 \pm 10$ & $7 \pm 2$ & & $4 \pm 5$ & 5 Yes/9 no & $217 \pm 62$ & $7 \pm 2$ & $\begin{array}{l}2 \text { Nonsurvivors/ } \\
12 \text { survivors }\end{array}$ \\
\hline
\end{tabular}


Table 2 Lung mechanics, gas exchange, and hemodynamics data

\begin{tabular}{|c|c|c|c|c|c|c|}
\hline Variable & $\begin{array}{l}\text { PEEP } 5 \text { incremental } \\
\text { phase }\end{array}$ & $\begin{array}{l}\text { PEEP } 10 \text { incremental } \\
\text { phase }\end{array}$ & PEEP 15 & $\begin{array}{l}\text { PEEP } 10 \text { decremental } \\
\text { phase }\end{array}$ & $\begin{array}{l}\text { PEEP } 5 \text { decremental } \\
\text { phase }\end{array}$ & $\begin{array}{l}\text { Friedman test } \\
p \text { value }\end{array}$ \\
\hline$\overline{V_{T}, \mathrm{ml} / \mathrm{kg} \mid \mathrm{IBW}}$ & $7.4[7.0-7.8]$ & $7.5[7.2-7.8]$ & $7.6[7.4-7.8]$ & $7.6[7.4-7.8]$ & $7.6[7.4-7.8]$ & 0.171 \\
\hline $\mathrm{RR}$, breaths/minute & 15 [14-16] & 16 [15-18] & 16 [14-18] & 16 [14-18] & 15 [14-18] & 0.275 \\
\hline$M V, L / m i n u t e$ & $6.4[5.8-6.6]$ & $6.9[6.4-7.7]$ & $6.8[6.5-8.0]$ & $6.8[6.5-8.4]$ & $6.8[6.4-7.8]$ & 0.222 \\
\hline Ppeak, $\mathrm{cmH}_{2} \mathrm{O}$ & $21[19-28]$ & $28[26-30]^{\mathrm{a}}$ & $34[32-35]^{a, b}$ & $27[25-30]^{a, c}$ & $23[21-28]^{b, c, d}$ & $<0.001$ \\
\hline Pplat, $\mathrm{cmH}_{2} \mathrm{O}$ & 15 [14-19] & $21[20-23]^{a}$ & $26[25-27]^{a, b}$ & $20[18-22]^{a, b, c}$ & $15[13-20]^{b, c, d}$ & $<0.001$ \\
\hline Driving pressure, $\mathrm{cmH}_{2} \mathrm{O}$ & $10[10-15]$ & 11 [10-13] & $12[10-12]$ & $10[8-12]$ & $10[8-15]$ & 0.100 \\
\hline $\mathrm{Crs}, \mathrm{ml} / \mathrm{cmH}_{2} \mathrm{O}$ & $39[32-47]$ & 38 [34-44] & 38 [34-43] & $43[35-57]$ & $45[30-52]$ & 0.100 \\
\hline $\mathrm{PaCO}_{2}, \mathrm{mmHg}$ & $53.8[49.1-59.0]$ & $53.3[49.2-58.0]$ & $54.0[50.4-59.7]$ & $52.2[47.1-56.1]$ & $51.8[44.7-57.5]$ & 0.246 \\
\hline $\mathrm{PaO}_{2} / \mathrm{FiO}_{2}, \mathrm{mmHg}$ & 233 [159-286] & 234 [163-279] & 255 [178-292] & 253 [203-320] & $246[172-304]$ & 0.611 \\
\hline $\mathrm{pH}$ & $7.33[7.30-7.39]$ & $7.34[7.30-7.41]$ & $7.32[7.29-7.40]$ & $7.34[7.29-7.38]$ & $7.34[7.31-7.39]$ & 0.170 \\
\hline MAP, $\mathrm{mmHg}$ & $70[66-85]$ & 76 [67-83] & $71[64-76]$ & $74[66-80]$ & 78 [70-82] & 0.490 \\
\hline $\mathrm{HR}$, beats/minute & 76 [72-86] & $76[68-84]^{a}$ & $72[67-84]^{a}$ & $73[64-83]^{\mathrm{a}}$ & 77 [63-85] & 0.021 \\
\hline
\end{tabular}

Abbreviations: PEEP Positive end-expiratory pressure, $R M$ Recruitment maneuver, $V_{T}$ Tidal volume, $I B W$ Ideal body weight, $R R$ Respiratory rate, $M V$ Minute ventilation, Ppeak Peak airway pressure, Pplat Plateau airway pressure, $\mathrm{Crs}$ Respiratory system compliance, $\mathrm{PaCO}_{2}$ Partial pressure of carbon dioxide in arterial blood, $\mathrm{PaO}_{2} / \mathrm{FiO}_{2}$ Ratio of partial pressure of oxygen in arterial blood to fraction of inspired oxygen, MAP Mean arterial pressure, $H R$ Heart rate Data are expressed as median [IQR]

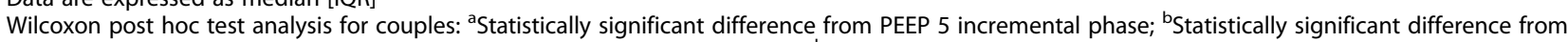

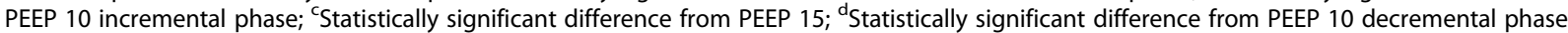

Table 3 Electrical impedance tomography and pressure-volume curve data

\begin{tabular}{|c|c|c|c|c|c|c|}
\hline Variable & $\begin{array}{l}\text { PEEP } 5 \text { incremental } \\
\text { phase }\end{array}$ & $\begin{array}{l}\text { PEEP } 10 \text { incremental } \\
\text { phase }\end{array}$ & PEEP 15 & $\begin{array}{l}\text { PEEP } 10 \text { decremental } \\
\text { phase }\end{array}$ & $\begin{array}{l}\text { PEEP } 5 \text { decremental } \\
\text { phase }\end{array}$ & $\begin{array}{l}\text { Friedman } \\
\text { test } p \text { value }\end{array}$ \\
\hline Nondependent silent spaces, \% & $0.4[0-3.3]$ & $1.3[0-3.9]$ & $1.4[0.4-4.3]$ & $1.7[0.5-3.0]$ & $0.7[0.1-2.2]$ & 0.109 \\
\hline Dependent silent spaces, \% & $16.3[11.7-17.9]$ & $12.3[9.2-15.2]^{\mathrm{a}}$ & $8.7[6.2-11.1]^{a, b}$ & $10.4[8.0-12.7]^{a, c}$ & $13.6[9.1-16.2]^{\mathrm{a}, c, \mathrm{~d}}$ & $<0.001$ \\
\hline $\begin{array}{l}\text { Center of ventilation } \\
\text { ventral-dorsal, } \%\end{array}$ & $41.9[38.1-48.8]$ & $46.3[41.8-50.8]^{\mathrm{a}}$ & $49.4[46.9-54.8]^{\mathrm{a}, \mathrm{b}}$ & $47.7[44.3-52.3]^{a, c}$ & $43.2[40.9-50.9]^{a, c, d}$ & $<0.001$ \\
\hline $\begin{array}{l}\text { Regional compliance (ROI 4), } \\
\mathrm{ml} / \mathrm{cmH}_{2} \mathrm{O}\end{array}$ & $3.09[1.21-4.95]$ & $4.32[2.92-6.03]^{a}$ & $5.90[4.63-6.8]^{a, b}$ & $6.01[4.53-6.53]^{a, b}$ & $4.27[2.64-5.34]^{\mathrm{c,d}}$ & $<0.001$ \\
\hline $\begin{array}{l}\text { Regional compliance (ROI 3), } \\
\mathrm{ml} / \mathrm{cmH}_{2} \mathrm{O}\end{array}$ & $10.52[7.74-12.27]$ & $12.32[8.64-14.03]^{\mathrm{a}}$ & $13.12[10.41-14.96]^{a, b}$ & $13.10[10.77-17.35]^{a, b}$ & $11.25[9.11-14.5]^{\mathrm{a}, \mathrm{d}}$ & $<0.001$ \\
\hline $\begin{array}{l}\text { Regional compliance (ROI 2), } \\
\mathrm{ml} / \mathrm{cmH}_{2} \mathrm{O}\end{array}$ & $13.9[12.24-18.97]$ & $13.55[12.82-17.06]$ & $13.09[11.07-15.93]^{b}$ & $14.95[12.59-19.32]^{b, c}$ & $14.74[11.38-20.21]$ & 0.026 \\
\hline $\begin{array}{l}\text { Regional compliance (ROI 1), } \\
\mathrm{ml} / \mathrm{cmH}_{2} \mathrm{O}\end{array}$ & $10.53[7.51-13.27]$ & $7.89[5.93-9.73]$ & $6.15[4.63-8.15]^{\mathrm{a}, \mathrm{b}}$ & $7.68[6.95-10.96]^{c}$ & $10.98[6.26-12.58]^{c}$ & $<0.001$ \\
\hline Tidal distribution index & $1.9[1.4-2.9]$ & $1.3[0.8-1.7]^{\mathrm{a}}$ & $1.0[0.7-1.2]^{\mathrm{a}, \mathrm{b}}$ & $1.3[1.1-1.7]^{a, c}$ & $1.8[1.4-2.2]^{a, c}$ & $<0.001$ \\
\hline $\begin{array}{l}\text { Regional compliance } \\
\text { dependent lung, } \\
\mathrm{ml} / \mathrm{cmH}_{2} \mathrm{O}\end{array}$ & $11.9[10.4-16.7]$ & $17.7[12.3-19.2]^{a}$ & $19.1[14.2-21.3]^{\mathrm{a}, \mathrm{b}}$ & $18.9[15.7-22.8]^{\mathrm{a}, \mathrm{b}}$ & $16.0[12.3-19.8]^{\mathrm{a}, \mathrm{d}}$ & $<0.001$ \\
\hline $\begin{array}{l}\text { Regional compliance } \\
\text { nondependent lung, } \\
\mathrm{ml} / \mathrm{cmH}_{2} \mathrm{O}\end{array}$ & $25.3[21.3-30.4]$ & $22.7[19.5-25.8]$ & $20.0[16.6-22.8]^{\mathrm{b}}$ & $24.3[18.7-28.5]^{c}$ & $26.4[17.5-30.7]$ & $<0.001$ \\
\hline$\Delta \mathrm{EELV}, \mathrm{ml}$ & 170 [132-242] & $495[411-565]^{a}$ & $800[638-943]^{a, b}$ & $435[336-574]^{\mathrm{a}, \mathrm{c}}$ & $190[133-262]^{b, c, d}$ & $<0.001$ \\
\hline$\triangle \mathrm{EELI}, \mathrm{ml}$ & 170 [105-260] & $559[404-716]^{a}$ & $1190[903-1378]^{a, b}$ & $777[500-930] \mathrm{a}, \mathrm{b}, \mathrm{c}$ & $270[191-410]^{a, b, c, d}$ & $<0.001$ \\
\hline $\begin{array}{l}\text { Recruitment } \\
\text { P-V curve, } \mathrm{ml}\end{array}$ & Baseline & 87.60 [32.20-119.00] & 114.50 [71.50-171.00] & $-82.20[-164.70$ to 3.00$]$ & $-101.20[-158.50$ to -28.00$]$ & \\
\hline $\begin{array}{l}\text { Recruitment } \\
\text { P-V curve, } \mathrm{ml} / \mathrm{kg} \text { IBW }\end{array}$ & Baseline & $1.32[0.66-2.18]$ & $2.09[1.05-3.22]$ & $-1.61[-3.26$ to 0.04$]$ & $-1.65[-2.22$ to -0.59$]$ & \\
\hline
\end{tabular}




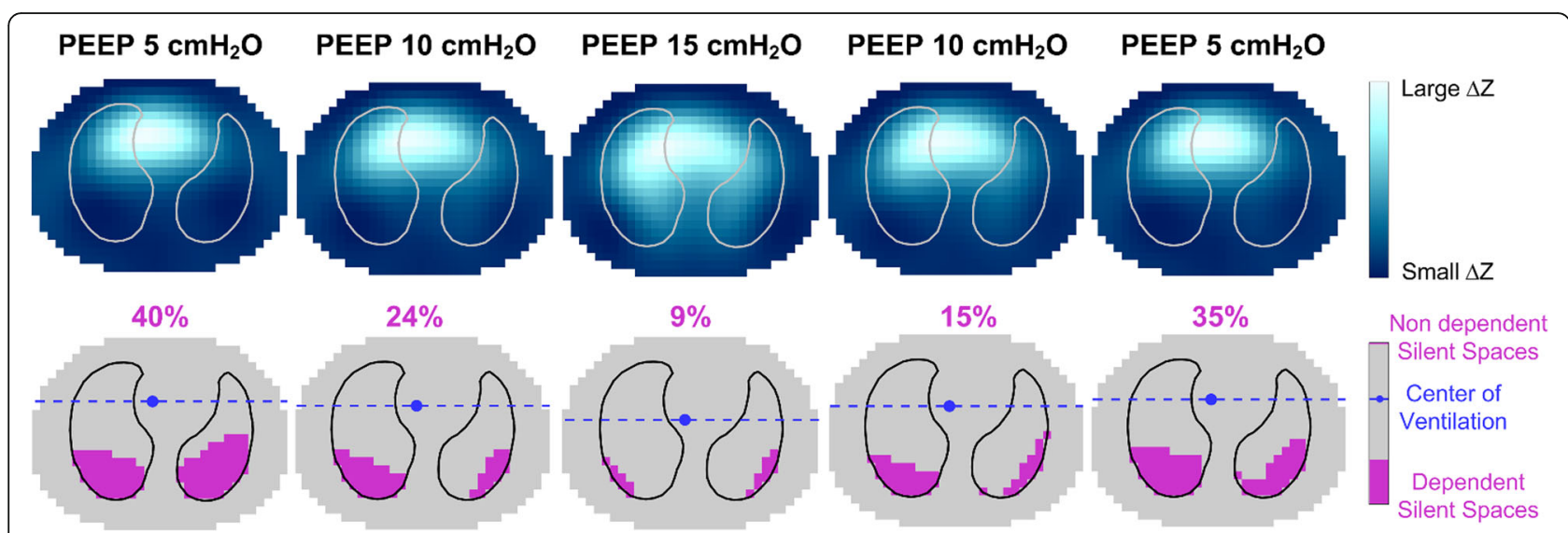

Fig. 1 Regional impedance map and "silent spaces" values during the different study phases in a representative patient. The impedance change maps $(\Delta Z)$ during the tidal breath are shown in the upper row for each step of the protocol; in the lower row, the corresponding level of silent spaces and center of ventilation are reported. Upon incrementally increasing positive end-expiratory pressure (PEEP), the percentage of dependent silent spaces decreased, whereas the opposite was true for decreasing PEEP levels

moving from the dorsal to the ventral part of the lung, the potential for recruitment decreased toward ROI 1, in which regional compliance decreased by $60 \%$.

\section{Discussion}

The main findings of this study are as follows: (1) PEEPinduced changes in EIT-derived poorly ventilated areas in the dependent lungs (DSSs) correlate with recruitment determined by the P-V curve, and (2) the reduction of DSS, obtained by progressive increases of PEEP, is associated with a more homogeneous distribution of ventilation and improved regional compliance of the dependent portions of the lung; however, higher levels of PEEP were associated with lower compliance of the nondependent part of the lung, which might indicate overdistention.

In the present study, we compared the EIT imaging technique with the P-V curve of the respiratory system to explore the hypothesis that these two methods deliver similar information about PEEP-induced lung recruitment. Silent spaces are a new EIT-derived parameter aimed at identifying areas of the lung in which air content changes minimally during tidal ventilation, potentially representing collapse or overdistention [22]. We hypothesized that changes in silent spaces, representing

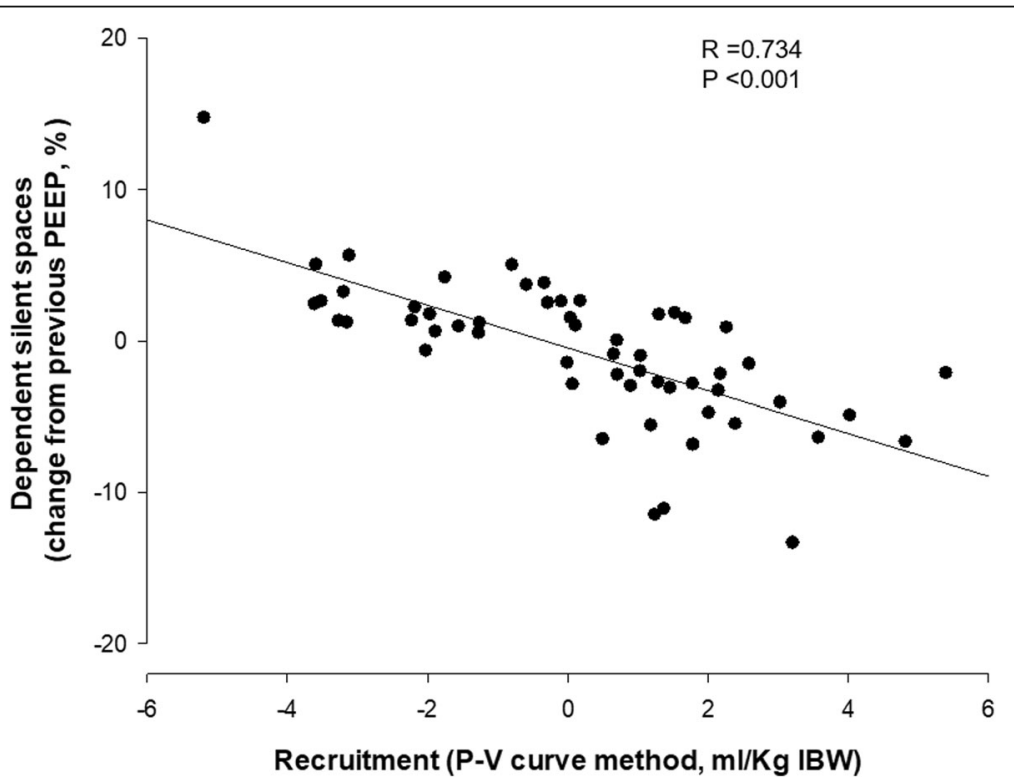

Fig. 2 Correlation between dependent silent spaces and recruited lung volume assessed by pressure-volume (P-V) curve. The recruited volume determined by the shift in lung volumes between the P-V curves performed at different levels of positive end-expiratory pressure (PEEP) correlated inversely with the percentage change in dependent silent spaces. IBW Ideal body weight 
changes in functional lung size, would also have been seen in the P-V curve as changes of recruited lung volume. Confirming our hypothesis, changes in DSS observed with EIT were statistically correlated with changes of lung volume measured by the P-V curve. Although the response to changes in PEEP and to the RM was heterogeneous in terms of lung volume and DSS changes, the two parameters changed accordingly (Fig. 2) because the increase/decrease of lung volume was associated with an opposite change of DSS (Table 3). Interestingly, the PEEP level corresponding to the lowest value of DSS was $15 \mathrm{cmH}_{2} \mathrm{O}$ in $12(86 \%)$ of the patients and $10 \mathrm{cmH}_{2} \mathrm{O}$ in $2(14 \%)$ of the patients (Additional file 1: Table S1).

The application of PEEP is a key but still challenging element of lung-protective ventilation, one of its effects being the redistribution of ventilation toward dependent lungs, which results in a more homogeneous aeration [34]. Because this technique provides information about regional lung ventilation [35], several indexes addressing ventilation homogeneity have been proposed [21], and EIT has been shown to be useful for assessing the effects of PEEP on the distribution of ventilation [36-41].

The TDI is used to evaluate the ratio of $V_{T}$ distributed to the nondependent and dependent lung. This index is an indirect signal of the homogeneity of the tidal ventilation. Our data show that incremental PEEP levels resulted in significant recruitment and a reduction of value of TDI closer to 1 , which implies more homogeneous ventilation by a shift of ventilation toward dorsal regions. This phenomenon is also demonstrated by the modification of the CoV: The increased change of the $\mathrm{CoV}$ toward $50 \%$ suggests that the tidal ventilation is moved toward the dependent lung regions. This index, in fact, changes significantly $(p<0.001)$ from PEEP $5 \mathrm{cmH}_{2} \mathrm{O}$ (41.9\%) to PEEP $15 \mathrm{cmH}_{2} \mathrm{O}$ (49.4\%). Interestingly, TDI indicated the most homogeneous distribution of ventilation at PEEP 15, 10, and $5 \mathrm{cmH}_{2} \mathrm{O}$ in 9 (64\%), 4 (28\%), and 1 (7\%) patients, respectively (Additional file 1: Table S1). These results show that different PEEP levels were able to achieve better lung homogeneity; indeed, tailored mechanical ventilation reducing lung inhomogeneity might decrease regional lung stress [42] and improve patient survival [43].

The use of silent spaces as a bedside method to determine the recruitment of functional lung volume has many advantages compared with the P-V curve because the monitoring is breathwise and continuous, providing local information. Furthermore, it does not require the use of high doses of sedatives or muscle relaxants.

EIT allows for assessment of regional lung mechanics on a pixel basis by tracking changes in regional lung compliance [44]. Mauri and colleagues showed that rising PEEP levels reduced lung strain and increased EELV, but at the expense of nondependent lung overinflation [39]. In our study, dependent regional compliance appeared to significantly increase rising PEEP levels, whereas nondependent regional compliance acted inversely, suggesting that higher PEEP can be associated with the risk of overdistention of that region. The determination of regional lung compliance might further support PEEP selection as the value that balances recruitment of dependent lung with "acceptable" overdistention of the nondependent one. Hence, the information obtained by EIT can be clinically relevant because the interpretation of global respiratory mechanics is often misleading in patients undergoing mechanical ventilation. In fact, global respiratory mechanics, like the static P-V curve, can only summarize overlapping information stemming from several ventilated units with different mechanical behaviors [45-47]. Indeed, the linear part of a static P-V curve may result from the overlap of already overdistended units and those that are opening during inspiration. Thus, a combination of different parameters obtained by EIT could reflect in more detail the properties of different lung regions that remain unrecognized by global assessments of respiratory mechanics.

Our study has some limitations. First, the method used to determine $\triangle E E L V$ requires the removal of PEEP for a limited number of breaths; hence, we cannot exclude a potential alveolar derecruitment between steps. However, the correlation between the two methods should not have been affected, because $\triangle E E L V$ was calculated at the end of data collection for each step, and its determination was always obtained during the same condition, making the influence on the quality of our data limited. Second, EIT imaging covers only the central part of the lungs (approximately 50\%) close to where the EIT belt is positioned. Third, we enrolled both patients with AHRF and patients with ARDS, in keeping with previous studies [39], but this might have introduced some heterogeneity of the population. Fourth, the number of patients enrolled in this physiological study was low but was in keeping with previous studies in this field [39]. Fourth, further studies are needed to integrate silent spaces into a clinical protocol for bedside selection of personalized PEEP, despite the fact that our study does not suggest a straightforward protocol to select PEEP on the basis of DSSs. Finally, further studies are required to find out if the variation of silent spaces determined by EIT is also correlated with recruitment in spontaneously breathing patients so that these spaces could be used to set a personalized level of PEEP. However, a reference standard different from P-V curve analysis should be used in that context.

\section{Conclusions}

Changes in EIT-derived DSSs induced by PEEP correlate with lung recruitment assessed by the P-V curve. Although the averaged maximal reduction of DSSs in our population was obtained at a PEEP of $15 \mathrm{cmH}_{2} \mathrm{O}$, 
worsening of regional nondependent lung compliance suggested some degree of overdistention. EIT seems to be a promising bedside tool for dynamic detection of regional changes in lung volumes due to recruitment and overdistention, potentially yielding useful information to select personalized PEEP.

\section{Additional file}

Additional file 1: Variation of poorly ventilated lung units (silent spaces) measured by electrical impedance tomography to dynamically assess recruitment. Additional information about the manuscript methods and additional data analysis are provided. Figure S1. Study protocol. Study protocol consisted of five consecutive phases. Figure S2. Hyperinflation (\%) and nondependent lung compliance $\left(\mathrm{ml} / \mathrm{CmH}_{2} \mathrm{O}\right)$ during the decremental step of the protocol. Hyperinflation (\%) and nondependent lung compliance $\left(\mathrm{ml} / \mathrm{cmH}_{2} \mathrm{O}\right)$ during the decremental step of the protocol. The hyperinflation value is expressed as a percentage of the total pixels and is relative to the last step of the PEEP titration trial (in this case, PEEP $=5 \mathrm{cmH}_{2} \mathrm{O}$ ). (ZIP $\left.178 \mathrm{~kb}\right)$

\section{Abbreviations}

AHRF: Acute hypoxemic respiratory failure; ARDS: Acute respiratory distress

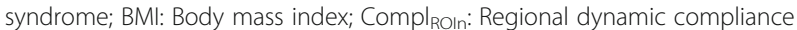
for each region of interest; CoV: Center of ventilation; Crs: Respiratory system compliance; DSS: Dependent silent spaces; $\Delta$ EELI: Change in end-expiratory lung impedance; $\Delta \mathrm{EELV}$ : Change in end-expiratory lung volume; EIT: Electrical impedance tomography; $\mathrm{FiO}_{2}$ : Fraction of inspired oxygen; HR: Heart rate; IBW: Ideal body weight; ICU: Intensive care unit; MAP: Mean arterial pressure; MV: Minute ventilation; NSS: Nondependent silent spaces; $\mathrm{PaCO}_{2}$ : Partial pressure of carbon dioxide in arterial blood; PPao: Pressure signal recorded at the airway opening; $\mathrm{PaO}_{2}$ : Partial pressure of oxygen in arterial blood; PEEP: Positive end-expiratory pressure; PEEPtot: Total positive end-expiratory pressure; Pplat: Plateau pressure; P-V: Pressure-volume; RM: Recruitment maneuver; ROI: Region of interest; RR: Respiratory rate; SAPS II: Simplified Acute Physiology Score II; SOFA: Sequential Organ Failure Assessment; TDI: Tidal distribution index; VILI: Ventilator-induced lung injury; $V_{T}$ : Tidal volume; $V_{\text {TDEP: }}$ Dependent lung tidal volume; $V_{\text {TNON-DEP: Nondependent }}$ lung tidal volume; $V_{\text {TROI: }}$ Regional tidal volume

\section{Acknowledgements}

We thank the nursing and medical staff of the intensive care unit at Sant'Anna Hospital, Ferrara, Italy.

\section{Funding}

The present study was supported by institutional funding from the University of Ferrara, Italy. Swisstom AG supported the study by granting use of an electrical impedance tomography system free of charge, but it had no role in study conception, design, and completion.

\section{Availability of data and materials}

Data-sharing consent was not obtained. The Ethics Committee of Ferrara (Italy) advised us that public sharing of our data would not be compatible with Italian legislation. Requests for data access may be sent to m.voci@ospfe.it. Such requests will be evaluated individually by the research office at San'Anna Hospital (Ferrara) according to the Italian personal data act.

\section{Authors' contributions}

SS, GS, CT, and CAV conceived of and coordinated the study, participated in its design, and helped to draft and review the manuscript. TM contributed to study conception and interpretation of data and was involved in revising the manuscript. CT, GS, SS, and RR contributed to acquisition, analysis, and interpretation of data and were involved in revising the manuscript. SHB and ADW contributed technical help during data analysis and revision of the final manuscript. GS and CT performed the statistical analysis and helped to carry out the data analysis. AP reviewed the manuscript constructively. All authors meet all autorship requirements of the International Commitee of Medical Journal Editors. All authors read and approved the final manuscript.

\section{Ethics approval and consent to participate}

The study was approved by the ethics committee of the Sant'Anna Hospital, Ferrara, Italy (protocol no. 141285), and registered with ClinicalTrials.gov (NCT02907840).

\section{Consent for publication}

Written informed consent was obtained from the patients or their relatives for publication of their individual details. The consent forms are held by the authors and are available for review by the Editor-in-Chief of this journal.

\section{Competing interests}

The authors declare that they have no competing interests.

\section{Publisher's Note}

Springer Nature remains neutral with regard to jurisdictional claims in published maps and institutional affiliations.

\section{Author details}

${ }^{1}$ Department of Morphology Surgery and Experimental Medicine, Section of Anesthesia and Intensive Care, University of Ferrara, 8, Aldo Moro, 44124 Ferrara, Italy. ${ }^{2}$ Department of Anesthesia, Critical Care and Emergency, Fondazione IRCCS (Istituto di Ricovero e Cura a Carattere Scientifico) Ca' Granda, University of Milan, Milan, Italy. ${ }^{3}$ Swisstom AG, Landquart, Switzerland. ${ }^{4}$ Egalen GmbH, Lauenburg, Germany.

Received: 31 October 2017 Accepted: 26 December 2017 Published online: 31 January 2018

\section{References}

1. ARDS Definition Task Force. Acute respiratory distress syndrome: the Berlin Definition. JAMA. 2012;307:2526-33.

2. Gattinoni L, Caironi $P$, Cressoni $M$, et al. Lung recruitment in patients with the acute respiratory distress syndrome. N Engl J Med. 2006;354:1775-86.

3. Slutsky AS, Ranieri VM. Ventilator-induced lung injury. N Engl J Med. 2013:369(22):2126-36.

4. Gattinoni L, Marini JJ, Pesenti A, et al. The "baby lung" became an adult. Intensive Care Med. 2016;42(5):663-73.

5. Dreyfuss D, Saumon G. Ventilator-induced lung injury: lessons from experimental studies. Am J Respir Crit Care Med. 1998;157(1):294-323.

6. Bellani G, Guerra L, Musch G, et al. Lung regional metabolic activity and gas volume changes induced by tidal ventilation in patients with acute lung injury. Am J Respir Crit Care Med. 2011;183(9):1193-9.

7. Mauri T, Eronia N, Abbruzzese $C$, et al. Effects of sigh on regional lung strain and ventilation heterogeneity in acute respiratory failure patients undergoing assisted mechanical ventilation. Crit Care Med. 2015;43(9):1823-31.

8. Lachmann B. Open up the lung and keep the lung open. Intensive Care Med. 1992;18(6):319-21.

9. De Matos GF, Stanzani F, Passos RH, et al. How large is the lung recruitability in early acute respiratory distress syndrome: a prospective case series of patients monitored by computed tomography. Crit Care. 2012;16(1):R4.

10. Writing Group for the Alveolar Recruitment for Acute Respiratory Distress Syndrome Trial (ART) Investigators. Effect of lung recruitment and titrated positive end-expiratory pressure (PEEP) vs low PEEP on mortality in patients with acute respiratory distress syndrome: a randomized clinical trial. JAMA. 2017;318(14):1335-45.

11. Brower RG, Lanken PN, Maclntyre N, et al. Higher versus lower positive end-expiratory pressures in patients with the acute respiratory distress syndrome. N Engl J Med. 2004;351(4):327-36.

12. Meade $\mathrm{MO}$, Cook DJ, Guyatt $\mathrm{GH}$, et al. Ventilation strategy using low tidal volumes, recruitment maneuvers, and high positive end-expiratory pressure for acute lung injury and acute respiratory distress syndrome: a randomized controlled trial. JAMA. 2008;299(6):637-45.

13. Goligher EC, Kavanagh BP, Rubenfeld GD, et al. Physiologic responsiveness should guide entry into randomized controlled trials. Am J Respir Crit Care Med. 2015;192(12):1416-9.

14. Maggiore SM, Jonson B, Richard JC, et al. Alveolar derecruitment at decremental positive end-expiratory pressure levels in acute lung injury: comparison with the lower inflection point, oxygenation, and compliance. Am J Respir Crit Care Med. 2001;164(5):795-801. 
15. Gattinoni $L$, Pesenti $A$, Avalli $L$, et al. Pressure-volume curve of total respiratory system in acute respiratory failure: computed tomographic scan study. Am Rev Respir Dis. 1987;136(3):730-6.

16. Ranieri VM, Eissa NT, Corbeil $C$, et al. Effect of PEEP on alveolar recruitment and gas exchange in ARDS patients. Am Rev Respir Dis. 1991;144:538-43.

17. Matamis D, Lemaire F, Harf A, et al. Total respiratory pressure-volume curves in the adult respiratory distress syndrome. Chest. 1984;86(1):58-66.

18. Froese $A B, M c C u l l o c h ~ P R$, Sugiura $M$, et al. Optimizing alveolar expansion prolongs the effectiveness of exogenous surfactant therapy in the adult rabbit. Am Rev Respir Dis. 1993;148(3):569-77.

19. Rimensberger PC, Cox PN, Frndova $\mathrm{H}$, et al. The open lung during small tidal volume ventilation: concepts of recruitment and "optimal" positive end-expiratory pressure. Crit Care Med. 1999:27(9):1946-52.

20. Rimensberger PC, Pristine G, Mullen BM, et al. Lung recruitment during small tidal volume ventilation allows minimal positive end-expiratory pressure without augmenting lung injury. Crit Care Med. 1999;27(9):1940-5.

21. Frerichs I, Amato MB, van Kaam AH, et al. Chest electrical impedance tomography examination, data analysis, terminology, clinical use and recommendations: consensus statement of the TRanslational EIT developmeNt stuDy group. Thorax. 2017;72(1):83-93.

22. Ukere A, März A, Wodack KH, et al. Perioperative assessment of regional ventilation during changing body positions and ventilation conditions by electrical impedance tomography. Br J Anaesth. 2016;117(2):228-35.

23. Acute Respiratory Distress Syndrome Network. Ventilation with lower tidal volumes as compared with traditional tidal volumes for acute lung injury and the acute respiratory distress syndrome. N Engl J Med. 2000;342(18):1301-8.

24. Ferrario D, Grychtol B, Adler A, et al. Toward morphological thoracic EIT: major signal sources correspond to respective organ locations in $\mathrm{CT}$. IEEE Trans Biomed Eng. 2012;59(11):3000-8.

25. Constantin JM, Grasso S, Chanques G, et al. Lung morphology predicts response to recruitment maneuver in patients with acute respiratory distress syndrome. Crit Care Med. 2010;38(4):1108-17.

26. Borges JB, Okamoto VN, Matos GF, et al. Reversibility of lung collapse and hypoxemia in early acute respiratory distress syndrome. Am J Respir Crit Care Med. 2006;174(3):268-78.

27. Radke OC, Schneider T, Heller AR, et al. Spontaneous breathing during general anesthesia prevents the ventral redistribution of ventilation as detected by electrical impedance tomography: a randomized trial. Anesthesiology. 2012;116:1227-34.

28. Frerichs I, Pulletz S, Elke $\mathrm{G}$, et al. Assessment of changes in distribution of lung perfusion by electrical impedance tomography. Respiration 2009;77: 282-91

29. Zick G, Elke G, Becher T, et al. Effect of PEEP and tidal volume on ventilation distribution and end-expiratory lung volume: a prospective experimental animal and pilot clinical study. PLoS One. 2013;8(8):e72675.

30. Suarez-Sipmann F, Böhm SH, Tusman G, et al. Use of dynamic compliance for open lung positive end-expiratory pressure titration in an experimental study. Crit Care Med. 2007;35(1):214-21.

31. Spadaro S, Scaramuzzo G, Bohm SH, et al. Silent spaces from electric impedance tomography in the bedside assessment of lung recruitment: a comparison with the pressure volume curve. Am J Respir Crit Care Med. 2017:195:A3018

32. Ranieri VM, Giuliani R, Fiore T, et al. Volume-pressure curve of the respiratory system predicts effects of PEEP in ARDS: "occlusion" versus "constant flow" technique. Am J Respir Crit Care Med. 1994;149:19-27.

33. Grivans C, Lundin S, Stenqvist O, et al. Positive end-expiratory pressure-induced changes in end-expiratory lung volume measured by spirometry and electric impedance tomography. Acta Anaesthesiol Scand. 2011:55(9):1068-77.

34. Gattinoni L, Pelosi P, Crotti S, et al. Effects of positive end-expiratory pressure on regional distribution of tidal volume and recruitment in adult respiratory distress syndrome. Am J Respir Crit Care Med. 1995;151(6):1807-14.

35. Mauri T, Bellani G, Confalonieri A, et al. Topographic distribution of tidal ventilation in acute respiratory distress syndrome: effects of positive end-expiratory pressure and pressure support. Crit Care Med. 2013;41(7):1664-73.

36. Blankman P, Hasan D, Erik G, et al. Detection of 'best' positive end-expiratory pressure derived from electrical impedance tomography parameters during a decremental positive end-expiratory pressure trial. Crit Care. 2014;18(3):R95.

37. Camporota L, Smith J, Barrett N, et al. Assessment of regional lung mechanics with electrical impedance tomography can determine the requirement for ECMO in patients with severe ARDS. Intensive Care Med. 2012;38(12):2086-7.

38. Cinnella G, Grasso S, Raimondo P, et al. Physiological effects of the open lung approach in patients with early, mild, diffuse acute respiratory distress syndrome: an electrical impedance tomography study. Anesthesiology. 2015;123(5):1113-21.

39. Mauri T, Eronia N, Turrini C, et al. Bedside assessment of the effects of positive end-expiratory pressure on lung inflation and recruitment by the helium dilution technique and electrical impedance tomography. Intensive Care Med. 2016;42(10):1576-87.

40. Meier $\mathrm{T}$, Luepschen $\mathrm{H}$, Karsten J, et al. Assessment of regional lung recruitment and derecruitment during a PEEP trial based on electrical impedance tomography. Intensive Care Med. 2008:34(3):543-50.

41. Karsten J, Grusnick C, Paarmann H, et al. Positive end-expiratory pressure titration at bedside using electrical impedance tomography in post-operative cardiac surgery patients. Acta Anaesthesiol Scand. 2015;59(6):723-2. 7.

42. Mead J, Takishima T, Leith D. Stress distribution in lungs: a model of pulmonary elasticity. J Appl Physiol. 1970;28(5):596-608.

43. Cressoni M, Cadringher $P_{1}$ Chiurazzi $C$, et al. Lung inhomogeneity in patients with acute respiratory distress syndrome. Am J Respir Crit Care Med. 2014;189(2):149-58.

44. Costa EL, Borges JB, Melo A, et al. Bedside estimation of recruitable alveolar collapse and hyperdistension by electrical impedance tomography. Intensive Care Med. 2009:35(6):1132-7.

45. Kunst PW, Bohm SH. Vazquez de Anda G, et al. Regional pressure volume curves by electrical impedance tomography in a model of acute lung injury. Crit Care Med. 2000:28:178-83.

46. Hickling KG. The pressure-volume curve is greatly modified by recruitment: a mathematical model of ARDS lungs. Am J Respir Crit Care Med. 1998;158:194-202

47. Hinz J, Gehoff A, Moerer O, et al. Regional filling characteristics of the lungs in mechanically ventilated patients with acute lung injury. Eur J Anaesthesiol. 2007:24(5):414-24

\section{Submit your next manuscript to BioMed Central and we will help you at every step:}

- We accept pre-submission inquiries

- Our selector tool helps you to find the most relevant journal

- We provide round the clock customer support

- Convenient online submission

- Thorough peer review

- Inclusion in PubMed and all major indexing services

- Maximum visibility for your research

Submit your manuscript at www.biomedcentral.com/submit
) Biomed Central 